\title{
TWO LEVEL NEGOTIATIONS IN BARGAINING OVER WATER
}

\author{
Alan Richards and Nirvikar Singh \\ Department of Economics \\ University of California, Santa Cruz \\ Santa Cruz, CA 95064 \\ arr@cats.ucsc.edu; boxjenk@cats.ucsc.edu
}

revised December 1996

\begin{abstract}
The paper analyzes the impact of a two-level game for water allocations. For a model with two domestic groups and two countries, and with both domestic and international negotiations, Nash bargaining theory is used to derive several propositions on the consequences of different bargaining rules for water allocations. The effect on international negotiations of the ability to commit to having domestic negotiations is examined. The importance of the nature and timing of complementary investments, and whether they are included in negotiations, in affecting the efficiency of the negotiated outcome is also explored.
\end{abstract}

This is a revised version of a paper presented at the International Game Theory Conference, Bangalore, India, January 2-6, 1996. We are grateful to the organizers of the conference, and for the helpful comments of participants, particularly Debraj Ray, Kalyan Chatterjee and Satya Das. We are most indebted to an anonymous referee for incisive comments that helped us to substantially improve the paper. Financial support was received from the University of California, Institute on Global Conflict and Cooperation; Indian Statistical Institute; and the University of California, Santa Cruz, Academic Senate and Division of Social Sciences. Nirvikar Singh also acknowledges the hospitality of the Centre for Development Economics, Delhi School of Economics, where he was a Senior Visiting Fellow during December 1995 and January 1996. We received helpful research assistance from Hui Miao. Remaining errors are our responsibility alone. 


\section{Introduction}

The problem of increasingly acute water scarcity plagues several regions of the developing world. Water demands are rapidly increasing, thanks to population growth, urbanization, and agricultural policies which usually subsidize water users. Nature meanwhile ensures that supplies in arid zones are inevitably limited. Compounding the problem is the fact that many countries or regions depend for water on rivers or aquifers which are shared with other nations/regions. Achieving agreement among water-scarce, often hostile nations has proved very difficult. Even in federal states such as India, inter-state conflict over water rights poses difficult issues.

Managing water scarcity will require two fundamental changes: domestic economic policies will have to be reformed to rationalize water use (e.g. World Bank, 1993); and transnational (or trans-state) agreements on water sharing must be forged. Each of these problems is difficult enough by itself; however, they are intimately interrelated. In effect, each national government is engaged in a "two-level game" (e.g., Putnam, 1988): it is simultaneously trying to reform its domestic water regime while also negotiating with its neighbors over how to share the river's resources. But a move in one game will typically have implications for the outcome of the other. International water negotiators are looking over their shoulders at domestic political conflicts over economic reform, while advocates and opponents of economic reform monitor international developments for its domestic implications.

There are several examples of such two-level games over water. The Colorado river has been the subject of negotiations between the United States and Mexico, as well as among the riparian states in the U.S. ${ }^{1}$. Sharing the waters of the Ganges river has been a point of contention between India and Bangladesh for several decades, while both countries have had to devise schemes for apportioning their own shares among different user groups and/or regions $^{2}$. The Indus and its tributaries became the focus of intense bargaining between India and Pakistan after India's partition in 1947. Simultaneously, India had to allocate its share of water from this basin to several different states ${ }^{3}$. Finally, Israel, Jordan, and the Palestinian National Authority, are negotiating over sharing the Jordan and Yarmouk rivers, as well as mountain aquifers, while Israel and Jordan face issues of reallocating water between urban and rural users internally ${ }^{4}$.

${ }^{1}$ See Friedkin (1987) and Ramana (1992), pp. 68-69.

${ }^{2}$ See Crow (1995), Chaudry and Siddigi (1987), National Water Development Agency (1992).

${ }^{3}$ See Barrett (1994) and Dhillon (1983).

${ }^{4}$ See Fisher (1995), Just, Netanyahu and Horowitz (1996). 
In the above examples, there are often more than two players at the subnational level. As a first approximation, we focus on only two groups within a country. One may think of this as "urban" versus "agricultural" interests; in fact, the interests of these groups are often in conflict. For example, the city of Amman faces increasingly serious water shortages while farmers in the (irrigated) Jordan Valley enjoy substantial subsidies to grow water-intensive crops such as bananas, in which Jordan has no comparative advantage. Alternatively, we may think of the groups as political entities, e.g., the states of Punjab and Haryana in India.

In this paper, we begin a theoretical study of this process of the interaction of domestic economic reform (viewed here as domestic negotiation over water allocations) and international water negotiation using the theory of cooperative bargaining The structure of the paper is as follows. In section 2, we construct a specific model of the two-level bargaining process, capturing the key feature of two levels of negotiation in a framework of Nash cooperative bargaining. Although one might object that this neglects the highly conflictual nature of actual water negotiations, the Nash and multiperson extension of the Nash solutions approximate the equilibria of, respectively, the Rubinstein (1982) noncooperative bargaining game, and a multiperson generalization of that noncooperative game, when those sequential games have high enough discount factors ${ }^{5}$. We assume two countries and two groups within each country or state; that state actors are benevolent; and that the initial allocation of water is sub-optimal for either of two reasons: 1) formerly water was not scarce and hence institutions have arisen which now no longer serve to allocate water efficiently, or 2) the initial bargaining conditions have changed. It follows that transfers are necessary to achieve Pareto efficiency. We examine several alternative (simultaneous and sequential) cooperative bargaining structures, and derive some equivalence results and welfare comparisons. Taken together, our results provide a demonstration of why there is often disagreement not only over water, but even over how to negotiate about water. The form of negotiations (the institutional arrangements) have very different consequences for different actors. A key feature in our framework is that being able to commit to domestic negotiations can improve the bargaining position at the international level ${ }^{6}$.

${ }^{5}$ See Harsanyi (1977), pp. 110-112 for a basic discussion of the relationship between cooperative and noncooperative games, and Binmore, Rubinstein and Wolinsky (1986) and Krishna and Serrano (1995) for analyses of the connection between the axiomatic approach and the sequential strategic approach to bargaining. The latter two papers show that the Nash and multiperson extension of the Nash solutions approximate the equilibria of, respectively, the Rubinstein (1982) noncooperative bargaining game, and a multiperson generalization of that noncooperative game, when those sequential games have high enough discount factors. Thus, we can justify our approach as being a shortcut, approximating the outcomes of noncooperative games, even when the assumption of cooperative behavior is questionable.

${ }^{6}$ Of course, this is not the only possible consequence of domestic politics for international bargaining. Most obviously, strong domestic farm lobbies may make it more difficult for a national government to make concessions. The argument that "our hands are 
In section 3, we discuss the generalization of the model, to include the possibility of complementary, productive investments, and of noncooperative actions. Water by itself rarely gives utility; it must be stored, moved, channeled, pumped, and piped to be useful. Investments which enhance the utility of water may be local, national, or international. Here we focus on the impact of national investment on water negotiations. We offer three additional propositions in this extension of our basic two interest group/two country model. First, the optimal allocation of water in one country will depend on domestic investment in the other country, even in the absence of direct externalities, as long as such investment affects the marginal utility of water. Second, if domestic investment affects the marginal utility of water, then, even in the absence of direct externalities, negotiating only over water, and not over domestic investments leads to an inefficient outcome if domestic investments can be precommitted. Finally, whether or not domestic investments can be precommitted before internal negotiations, if they take place after international negotiations, then, in the absence of direct externalities, the outcome in terms of water allocation and domestic investments is efficient. Section 4 is a brief conclusion.

\section{Cooperative Bargaining Structures}

The structure of our model allows us to focus on a key issue, the nature of the interaction between international and domestic bargaining. We use a cooperative bargaining framework, assuming that parties to an agreement can commit to it We first restrict attention to the allocation of water only, ignoring for now the other dimensions of domestic and international negotiation ${ }^{7}$. In section 3, we introduce the important issue of investment. We first present the model and notation, followed by analysis.

\section{Model and Notation}

There are two nations or countries, denoted by A and B, and two groups in each country. To reduce multiple subscripts, we number the groups sequentially, from 1 to 4 . Groups 1 and 2 are in country A, while groups 3 and 4 are in country B. As suggested, these may be thought of as "city dwellers" and irrigated land farmers". There are two goods consumed by each group: water, denoted w, and a numeraire good, denoted y. There is no

tied" is often quite useful in negotiations, (e.g., Schelling,1960). Alternatively, an unfinished international water negotiation may retard domestic reform, as the negotiating parties fear that any domestic water-savings achieved through reform will reduce their ability to claim a larger share of international water. One obstacle to reform of domestic Jordanian water policy before the peace treaty with Israel was precisely the fear by some Jordanian officials that greater efficiency in Jordanian domestic water use would be seized upon by Israeli negotiators, who would argue that Jordan "needed less water".

${ }^{7}$ As a referee has pointed out, this means that some of our analysis is not specific to water issues only: the bargaining could be over any resource. We hope this generality can be viewed as a positive feature. 
collective decision problem within any group, so each group has a well-specified utility function. We assume for tractability that all utility functions are quasi-linear, so that utility is transferable, and all Pareto frontiers are straight lines or hyperplanes. This considerably simplifies analysis. We will attempt to relax this assumption in future work. Initial allocations of the goods are assumed to be available to each group, and are denoted by bars over the corresponding letters, e.g., $\bar{w}$. Hence, with this notation, the initial utility of group $\mathrm{i}$ is given by

$$
u_{i}\left(\overline{w_{i}}, \overline{y_{i}}\right)=v_{i}\left(\overline{w_{i}}\right)+\bar{y}_{\boldsymbol{i}}
$$

We assume that the functions $v_{\boldsymbol{i}}\left(w_{\boldsymbol{i}}\right)$ are strictly concave and differentiable. Within the countries, the total quantities of water available are $\bar{w}^{\boldsymbol{A}}, \bar{w}^{\boldsymbol{B}}$, in $\mathrm{A}$ and $\mathrm{B}$ respectively.

The essential problem faced by the bargainers is that the initial allocation of water is suboptimal, both across groups within a country and across countries. This can be explained by changing circumstances. Water may have been relatively abundant in the past, and all parties were able to get as much as they wanted at a zero price. As populations and economic values change, however, the allocation determined by historical circumstances and traditional institutional mechanisms may no longer be optimal. In addition, the climate for international negotiations may also fluctuate: it may be more propitious now than in the past.

We denote the optimal amounts of water by asterisks,e.g., $\boldsymbol{w}_{\boldsymbol{i}} *$ for group i. The conditions for the optimal allocation of water are given by the requirement that the marginal utility of water be equated for each group, i.e., $v^{\prime}\left(w_{i}^{*}\right)=v^{\prime}\left(w_{j} *\right)$. Clearly, such a solution, transferring water from one group to another, will not be feasible without some compensatory transfers. Thus we have that final utilities are given by

(2) $u_{i}\left(w_{i} *, y_{i} *\right)=v_{i}\left(w_{i} *\right)+y_{i} * \equiv v_{i}\left(w_{i} *\right)+\bar{y}_{i}+t_{i} *$

The identity above defines the optimal transfer for group $i$ as the difference between the final and initial amounts of the numeraire good. Unlike the optimal amounts of water, however, the transfers are not uniquely determined. Instead, they depend on the bargaining game. In particular, since we are going to use the Nash bargaining solution, the transfers will depend on the threat points of the parties engaged in bargaining. Note that where it is unambiguous, we will abbreviate expressions such as $\boldsymbol{u}_{\boldsymbol{i}}\left(\boldsymbol{w}_{\boldsymbol{i}} *, \boldsymbol{y}_{\boldsymbol{i}}^{*}\right)$ to $\boldsymbol{u}_{\boldsymbol{i}} *$.

It is instructive to provide an alternative institutional determination of the transfers, for comparison purposes. Suppose that the result of the negotiations is an agreement to recognize initial allocations of water as representing de facto property rights, with an international market for water also being created. Let the price of water be $\mathrm{p}_{\mathrm{w}}$. Then, as long as the price is set appropriately, there will be market clearing at the optimal allocation of water. To see this, consider the problem of group $i$, which is now to maximize

(3) $v_{\boldsymbol{i}}\left(w_{\boldsymbol{i}}\right)+\bar{y}_{\boldsymbol{i}}+\boldsymbol{p}_{w}\left(\bar{w}_{\boldsymbol{i}}-w_{\boldsymbol{i}}\right)$. 
The solution to this is to set the marginal utility of water equal to the price of water. Hence, all marginal utilities are equalized. Furthermore, there will be an excess supply or demand for water unless the price equals the shadow price of the constraint in the problem

(4) $\max \Sigma u_{\boldsymbol{i}}\left(w_{\boldsymbol{i}}, y_{\boldsymbol{i}}\right)$ subject to $\Sigma w_{\boldsymbol{i}}=\bar{w}$.

But with that price (which is the marginal utility of water for any of the groups at the optimum), the market solution will correspond to the optimal solution. The transfers are then the result of market transactions, with

(5) $t_{i}=p_{w}\left(\bar{w}_{\boldsymbol{i}}-w_{i}\right)$.

Returning to the bargaining case, at the optimum allocation of water, the transfers are not uniquely determined unless one specifies the bargaining game. Any cooperative bargaining game will depend on recognizing the set of Pareto optimal points in utility space. The equation of the utility possibility frontier is given by

(6) $\Sigma u_{i}\left(w_{i} *, y_{i}^{*}\right)=\Sigma v_{i}\left(w_{i} *\right)+\Sigma \overline{y_{i}} \equiv \boldsymbol{H}$

The identity above defines the maximum total utility available. Note that in writing the middle expression, we use the fact that the sum of the numeraire good is unaffected by the transfers, or the sum of the transfers is zero. A final piece of initial notation is given by

(7) $d_{i}=u_{i}\left(\overline{w_{i}}, \overline{y_{i}}\right)=v_{i}\left(\bar{w}_{i}\right)+\bar{y}_{i}$

Here the notation captures the fact that the initial utility level is potentially the disagreement payoff or threat point for the water bargaining game. We will introduce further notation as necessary, as we turn to analyzing several possible cases of bargaining.

\section{Domestic Negotiations Only}

To begin with, consider the case where only domestic negotiations and reallocation of water are possible. We will focus on country A, with the analysis for country B being parallel. Let $\boldsymbol{w}_{1} \boldsymbol{A}, \boldsymbol{w}_{2}{ }^{\boldsymbol{A}}$ denote the optimal allocation of water in country A, i.e., the solution to

(8) $\max v_{1}\left(w_{1}\right)+v_{2}\left(w_{2}\right)$ subject to $w_{1}+w_{2}=\bar{w}^{A}$

Furthermore, let $\mathrm{H}^{\mathrm{A}}$ be the maximized utility that results from this optimal allocation within country A. Using the Nash bargaining solution, the problem in country A is

(9) $\max \left(u_{1}-\boldsymbol{d}_{1}\right)\left(u_{2}-\boldsymbol{d}_{2}\right)$ subject to $u_{1}+u_{2}=\boldsymbol{H}^{\boldsymbol{A}}$

The solution is easily seen to be

$$
u_{1}^{D}=\frac{1}{2}\left(H^{A}+d_{1}-d_{2}\right), u_{2}^{D}=\frac{1}{2}\left(H^{A}+d_{2}-d_{1}\right)
$$

Focusing on group 1, the utility from the Nash bargaining solution can be rewritten more explicitly as

(11) $u_{1}^{D}=\frac{1}{2}\left[v_{1}\left(w_{1}^{A}\right)+v_{2}\left(w_{2}^{A}\right)+v_{1}\left(\bar{w}_{1}\right)-v_{2}\left(\bar{w}_{2}\right)\right]+\bar{y}_{1}$

Furthermore, the associated transfer is

(12) $t_{1}^{D}=\frac{1}{2}\left[\left(v_{2}^{A}-\bar{v}_{2}\right)-\left(v_{1}^{A}-\bar{v}_{1}\right)\right]$,

where we use the abbreviated notation. 
It is instructive to compare the Nash bargaining solution with the market solution, which, for group 1 , is given by $t_{1}^{D M}=v_{1}^{\prime}\left(w_{1}{ }^{\boldsymbol{A}}\right)\left(\bar{w}_{1}-w_{1}{ }^{\boldsymbol{A}}\right){ }^{8}$ Comparing this with (12), it is clear that the two approaches, bargaining and markets, give different answers in general. ${ }^{9}$

\section{International Negotiations Only}

Suppose that both countries agree that domestic negotiations will be effectively conducted at the international level, as a way of reaching an overall agreement in one step. This can be achieved by bringing all four groups simultaneously to the bargaining table. It may seem unusual for domestic groups to participate in international negotiations, but it is certainly feasible. With four groups, one can use Harsanyi's (1963) generalization of the Nash bargaining solution ${ }^{10}$. The problem is now to solve

(13) $\max \Pi_{i=1}^{4}\left(u_{i}-d_{i}\right)$ subject to $\Sigma_{i=1}^{4} u_{i}=H$.

Note that the disagreement payoffs here incorporate the assumption that separate domestic negotiations will not occur. The solution to the maximization is given by

(14) $u_{i}^{I}=\frac{1}{4} H+\frac{3}{4} d_{i}-\frac{1}{4} \sum_{j \neq i} d_{j}$

This implies a transfer for group i of

(15) $t_{\boldsymbol{i}}^{I}=\frac{1}{4} \sum_{j \neq i}\left[\left(v_{j}^{*}-\bar{v}_{j}\right)-\left(v_{i}^{*}-\bar{v}_{\boldsymbol{i}}\right)\right]$.

How does this outcome compare with the case where only domestic negotiations are possible? Clearly, greater efficiency is achieved by allowing reallocation of water across the two countries. However, the Nash bargaining solution above may not represent a Pareto improvement over the case of separate domestic bargaining. This is because the presence of new parties at the bargaining table affects the relative impact of the threat points. We may illustrate this with a simple example. Suppose that the utility functions for all four groups are identical, and given by $\ln \mathrm{w}_{\mathrm{i}}$, while the initial allocations of water are 2, 4, 6 and 8 for the four groups, respectively. It is possible to show that in this case, $u_{i}{ }^{I}>u_{i}{ }^{D}$ for each group. However, if the initial allocations of water are 2, 6, 6, 6, then group 2 is worse off in the allparty international negotiation. Essentially, in domestic negotiations, this group is in a strong position relative to group 1 in country A, through the impacts of the initial allocations on the threat points. This position is diluted by the presence of the other two groups in the

${ }^{8}$ Similar expressions can be derived for the second group in country A. In fact, since the transfers sum to zero, group 2's transfer is just the negative of group 1's. The utility expressions are symmetric. The same results can be derived for groups 3 and 4 in country B.

9 Note that the market solution depends linearly on the initial allocation, while the Nash bargaining solution depends on it nonlinearly, through the threat points of the two groups. Hence, it is not possible to make a general comparison of the two outcomes in terms of the magnitudes of the transfers.

${ }^{10}$ Harsanyi (1977), Ch. 10, provides a complete treatment. 
bargaining. To see this more generally, consider group 1, for example. From (10) and (14), we obtain

$u_{1}^{D}-u_{1}^{I}=\frac{1}{2}\left(H^{A}-d_{1}-d_{2}\right)-\frac{1}{4}\left(H-d_{1}-d_{2}-d_{3}-d_{4}\right)$

which is the difference in the gains from agreement in the two cases, and the first term can outweigh the second. We summarize the implications of this comparison in the following statement.

Proposition 1 In our two country model with two groups in each country, it is possible that a group may prefer to have only domestic negotiations over all-party international bargaining without the option of separate domestic negotiations.

\section{All-Party International Negotiations with Domestic Negotiations as Fallback}

An alternative possibility is that if international negotiations among all four groups fail, domestic bargaining can still take place. In this case, the participants in the international round should correctly assume that the domestic negotiations will succeed. The bargaining outcome is now the solution to

(16) $\max \Pi_{i=1}^{4}\left(u_{i}-u_{i}^{D}\right)$ subject to $\Sigma_{i=1}^{4} u_{i}=H$,

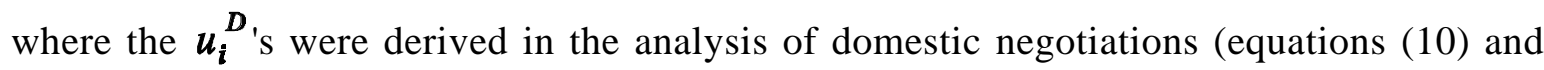
(11)). The solution is given by

(17) $u_{i}^{I D}=\frac{1}{4} H+\frac{3}{4} u_{i}^{D}-\frac{1}{4} \sum_{j \neq i} u_{j}^{D}$.

We will analyze this outcome further after we have presented some alternative possibilities for the conduct of international negotiations. In particular, it is realistic to consider situations where only nations bargain with each other, and within-country bargaining, among domestic groups, takes place separately.

\section{International Negotiations: If Successful, Followed by Domestic Negotiations}

Suppose that international negotiations take place between the two countries, where each national government has a purely utilitarian objective. This objective seems plausible in the absence of any bias towards one group or another. Clearly, other objectives are possible: the main point to note is that national governments are assumed to be benevolent. We assume here that domestic negotiations will take place only if the international negotiations are successful. This may seem restrictive, but it provides for a useful comparison with other cases. The assumption implies that the international negotiations take the initial allocation as defining the threat point.

With these assumptions, the Nash bargaining game for the international negotiations is given by

(18) $\max \left(u_{1}+u_{2}-d_{1}-d_{2}\right)\left(u_{3}+u_{4}-d_{3}-d_{4}\right)$ subject to $\Sigma_{i=1}^{4} u_{i}=H$.

The solution for country $\mathrm{A}$ is given by

$$
u_{A} \equiv \frac{1}{2}\left(H+d_{1}+d_{2}-d_{3}-d_{4}\right)
$$


with a similar expression for country B.

The domestic negotiations then take the outcome of international negotiations as a starting point for dividing the allocation and transfers within each country. We assume that, if the domestic negotiations break down, the gains from the international agreement can not be implemented. This implies that the threat points in the domestic negotiations are the $\mathrm{d}_{\mathrm{i}}$ 's. For example, for country $\mathrm{A}$, the Nash bargaining solution is given by

(20) $\max \left(u_{1}-d_{1}\right)\left(u_{2}-d_{2}\right)$ subject to $u_{1}+u_{2}=u_{A}$.

Analogously to the case of domestic negotiations alone, this can be solved to give, for groups 1 and 2 ,

(21) $u_{1}=\frac{1}{2}\left(u_{A}+d_{1}-d_{2}\right), \quad u_{2}=\frac{1}{2}\left(u_{A}+d_{2}-d_{1}\right)$.

Now a substitution for $\mathrm{u}_{\mathrm{A}}$ shows that the utility of group $\mathrm{i}$ is $\frac{1}{4} \boldsymbol{H}+\frac{3}{4} \boldsymbol{d}_{\boldsymbol{i}}-\frac{1}{4} \sum_{j \neq i} \boldsymbol{d}_{j}$.

But this is the same as in the case of four-way international negotiations, i.e., equation (14).

We state this as our second result.

Proposition 2 In our two country model with two groups in each country, four-way (grouplevel) international bargaining gives the same outcome as international bargaining at the national level, where in each case domestic negotiations do not occur if the international round of negotiations fails. In the case of national-level international bargaining, domestic negotiations follow its successful conclusion.

This equivalence result between two level and one level negotiations is useful, but the assumption that domestic negotiations only occur if the international round is successful may not be appropriate in all cases. Thus we turn to an alternative formulation of combined international and domestic negotiations.

\section{International Bargaining: A lways Followed by Domestic Bargaining}

We now consider the case where the international negotiations assume that, if they fail to reach an agreement, domestic negotiations will take place, as in the very first case we analyzed. Thus, the threat points for the groups are given by $u_{i}{ }^{D}$. We also assume that if international bargaining fails, negotiations at that level will not be reopened. In equilibrium, however, our assumptions imply that this will not occur: the international bargaining will achieve the cooperative outcome. This could arise, for example, if there were a limited political window of opportunity" which may pass: Jordan could get an agreement with an Israeli government headed by Rabin, but not by Shamir ${ }^{11}$. In this case, the Nash bargaining solution for the international negotiations is given by

(22) $\max \left(u_{1}+u_{2}-u_{1}^{D}-u_{2}^{D}\right)\left(u_{3}+u_{4}-u_{3}^{D}-u_{4}^{D}\right)$ subject to $\Sigma_{i=1}^{4} u_{i}=H$

The solution for country $\mathrm{A}$ is given by

11 Of course this example is merely meant to be suggestive, since there have been many other factors at work in the Middle East. 
(23) $\hat{u}_{A} \equiv \frac{1}{2}\left(H+H^{A}-H^{B}\right)$,

with a similar expression for country B. Domestic negotiations proceed based on this expression for the total utility, and again assuming that the international agreement can not be implemented without domestic agreement on how to internally divide the gains (so that the $\mathrm{d}_{\mathrm{i}}$ 's are the threat points), yielding

$$
u_{1}^{I D}=\frac{1}{2}\left(\hat{u}_{A}+d_{1}-d_{2}\right), \quad u_{2}^{I D}=\frac{1}{2}\left(\hat{u}_{A}+d_{2}-d_{1}\right) \text {. }
$$

We use the same notation as for the second four-way bargaining case: this is justified in Proposition 4 below. Substituting for $\hat{u}_{\boldsymbol{A}}$ yields an alternative expression for these utilities.

Now

$$
\text { (25) } \hat{u}_{A}-H^{A}=\frac{1}{2}\left(H+H^{A}-H^{B}\right)-H^{A}=\frac{1}{2}\left(H-H^{A}-H^{B}\right) \text {. }
$$

The last expression is clearly positive, as long as there are gains to reallocation of water between the two countries. Hence we have the following result (which contrasts with case 'I', in which some domestic group could prefer only domestic negotiations).

Proposition 3 In our two country model with two groups in each country, international bargaining which assumes that domestic negotiations will still occur if international agreement is not reached, followed by domestic negotiations, is preferred by all groups to domestic negotiations alone.

In Proposition 2, we demonstrated an equivalence result for particular cases of simultaneous and two-level negotiations, where domestic negotiations did not occur if the international bargaining failed to reach agreement. We have a similar equivalence result for all-party and two-level negotiations when, in each case, failure of international negotiations is assumed to be followed by successful domestic negotiations.

Proposition 4 In our two country model with two groups in each country, four-way international bargaining gives the same outcome as national level international bargaining, where in each case domestic negotiations are correctly assumed to occur if the international round of negotiations fails. In the case of national-level international bargaining, domestic negotiations also follow its successful conclusion

Proof The solution for the four-way bargaining in this case is, as given earlier,

$$
\text { (17) } u_{i}^{I D}=\frac{1}{4} H+\frac{3}{4} u_{i}^{D}-\frac{1}{4} \sum_{j \neq i} u_{j}^{D} \text {. }
$$

Substituting for the $u_{i}{ }^{D} s$, from (10) this reduces to, for example,

$$
u_{1}^{I D}=\frac{1}{4}\left(H+H^{A}-H^{B}\right)+\frac{1}{2}\left(d_{1}-d_{2}\right)
$$

with similar expressions for the other three groups.

Alternatively, with two level negotiations, from (23) and (24),

$$
u_{1}^{I D}=\frac{1}{2}\left(\hat{u}_{A}+d_{1}-d_{2}\right), \text { and } \hat{u}_{A} \equiv \frac{1}{2}\left(H+H^{A}-H^{B}\right)
$$


A simple substitution establishes the equivalence ${ }^{12}$.

Finally, we can also compare the two cases, with and without domestic negotiation following failure of the international negotiation. Consider group 1 for illustrative purposes. We have, after some simplification,

(28) $u_{1}^{I D}-u_{1}^{I}=\frac{1}{4}\left(H^{A}-H^{B}\right)+\frac{1}{2}\left(d_{1}-d_{2}\right)-\frac{3}{4} d_{1}+\frac{1}{4}\left(d_{2}+d_{3}+d_{4}\right)$

Hence we have

(29) $u_{1}^{I D}>u_{1}^{I} \Leftrightarrow H^{A}-\left(d_{1}+d_{2}\right)>H^{B}-\left(d_{3}+d_{4}\right)$

Since this last expressions just depends on country-level differences, it is easy to see that it will hold for group 2 as well. For groups 3 and 4 in country B, the inequality is reversed. Hence we have the following result.

Proposition 5 Consider countries' preferences between two negotiating arrangements. In the first, international bargainers assume that if they fail to reach agreement, domestic negotiations will proceed in both countries. In the second, international bargainers assume that domestic negotiations will not take place if an international agreement cannot be reached. The country which gains more from a domestic agreement prefers the first arrangement, whereas the other country will always have the opposite preference (i.e., prefers the second arrangement).

The intuition for the result is clear. The country that gains more from a domestic agreement improves its threat point more than the other country, and therefore gains in having negotiations which assume that a domestic agreement will always occur. This result also illustrates why there is sometimes difficulty in agreeing to how international negotiations are to be conducted.

12 Note that in general, two-level and all-party negotiations may not be equivalent, even for given assumptions about domestic negotiations, and which groups are to be allowed to participate at the international level may matter. We consider briefly the generalization of Propositions 2 and 4. First of all, it should be pointed out that these are not simply consequences of the consistency axiom, which is a property of the multiperson Nash bargaining solution. (See Krishna and Serrano, 1995, and Lensberg,1988.) In fact, this is demonstrated by observing that, even for the quasilinear utility case, the result does not apply if there are two groups in one country and only one in the other (this is done by simple calculations, omitted here). However, for the symmetric case, with two groups in each country, we can establish the following, for general utility functions. Suppose that the threat points in all-group, international bargaining are denoted by $\mathrm{x}_{\mathrm{i}}$. Then the equivalence result such as in the two propositions holds if and only if $x_{1}-x_{2}=d_{1}-d_{2}$ and $x_{3}-x_{4}=d_{3}-d_{4}$. The intuition here is that equivalence holds if the relative bargaining strengths of domestic groups vis-a-vis each other are unaffected at the different levels of negotiation. 


\section{Domestic Bargaining Followed by International Bargaining}

There are several possibilities to consider in this case. Assume that the domestic bargaining anticipates that the international bargaining will succeed if the domestic bargaining does ${ }^{13}$. Different assumptions are possible with respect to how the situation will be perceived if domestic bargaining fails: these will affect the threat point of the domestic bargaining game.

First, consider the case where it is expected that, if domestic bargaining fails, there will be no international negotiations. Then the threat points for the domestic groups in internal negotiations are the $\mathrm{d}_{\mathrm{i}}$ 's. Hence, the domestic negotiations anticipating the international agreement yield a bargaining game identical to the one where they are subsequent to the international agreement. If the latter is based on the expectation that domestic negotiations will still follow the failure of international bargaining, the solution will be identical to the previous case, labeled with the superscript ID.

Now consider the expectation that international negotiations will still go ahead, even if the domestic negotiations fail to reach an agreement. Again, if this international bargaining is of the kind that assumes domestic agreement will be reached whatever the international negotiation outcome (because internal negotiations can successfully reopen), we will get the 'ID' solution. If, on the other hand, the international bargaining that will take place in the absence of a prior domestic agreement assumes that domestic bargaining will fail or not take place if the international bargaining fails, we will get the second case outcome, indicated by superscript 'I'.

\section{Other Symmetric Cases}

Other symmetric cases (in terms of expectations) reduce to one of the previous three. For example, suppose that international negotiations come first, but there is the recognized possibility of reopening them if they succeed but the domestic negotiations fail, or if they fail. We argue that this reduces to the previous case, where domestic negotiations come first. There, we showed that the outcome would be one of the cases 'D', 'I', or 'ID'. Similarly, any chain of possibilities for reopening negotiations will reduce to one of these three cases. The salient issue in working out the outcome of each possible game is what is expected to happen if there is no immediate agreement, since this determines the threat point for the current negotiations. This is what matters for the equilibrium, rather than the exact sequence of the two levels of bargaining.

\section{A symmetric Cases}

${ }^{13}$ If international negotiations were expected to fail, or to not occur at all, this would reduce to the case of only domestic bargaining, which we considered first. 
Now suppose that international negotiations take place, but that, if they fail, domestic negotiations will take place only in country $\mathrm{B}^{14}$. The Nash product in the international bargaining is now

(30) $\left(u_{1}+u_{2}-d_{1}-d_{2}\right)\left(u_{3}+u_{4}-u_{3}^{D}-u_{4}^{D}\right)$.

Solving the two levels of the bargaining game yields, for group 1 in country A,

$$
u_{1}^{R I}=\frac{1}{4}\left(H-H^{B}\right)+\frac{3}{4} d_{1}-\frac{1}{4} d_{2},
$$

where the superscript 'RI' is meant to suggest that country A is more rigid or restricted in its position. It is a simple matter to check that

(32) $u_{1}^{R I}<\min \left\{u_{1}^{I}, u_{1}^{I D}\right\}$.

A similar result will obviously hold for group 2 in country A. Thus, being rigid in this way (failing to hold domestic negotiations when international negotiations fail) unambiguously hurts country A. For the groups in country B, we have (33) $u_{\boldsymbol{i}}^{R I}>\max \left\{u_{\boldsymbol{i}}^{I}, u_{\boldsymbol{i}}^{I D}\right\}, \mathrm{i}=3,4$.

If the roles of countries A and B are switched, we denote that case by 'IR', and the analogues of (32) and (33) will hold. These inequalities are used in discussing endogenous commitments to negotiate.

\section{Commitments to Negotiate}

The asymmetric cases allow us to tackle the question of how national governments will behave if they can make commitments regarding domestic negotiations. Up to now, we have assumed that whether domestic negotiations take place after the failure of international negotiations was exogenously given. Making it an endogenous choice creates a $2 \times 2$ noncooperative game that precedes the two levels of cooperative bargaining. Since the case indexed ' $\mathrm{I}$ ' is equivalent to the situation where both countries are rigid, and 'ID' is equivalent to the case where neither one is, equations (32) and (33) and their analogues when country B is rigid provide a simple solution: it is a dominant strategy for each national government to commit to having domestic negotiations, whatever the possible outcome of the international negotiations $^{15}$. The intuition is simple: doing so improves the threat point of the subsequent international bargaining game for each country. Note that one country will be better off, and the other worse off as a result of this commitment, compared to the case where neither commits: this follows from Proposition 5.

\section{Investment and Noncooperative Behavior}

${ }^{14} \mathrm{We}$ are grateful to a referee for suggesting this possibility, and the issue of commitments to negotiate discussed next.

15 Thus, even if only one country has this choice, it will exercise it in the manner indicated. This might be the case if the other country's politics are more fractious or rigid, so that only successful international cooperation will spur domestic agreement. 
In the model constructed in the previous section, there is essentially only one decision at stake: how much will suppliers of water be compensated? This may be determined by cooperative bargaining ${ }^{16}$, or by a market-type mechanism. We have suggested that bargaining is closer to actual practice than are market mechanisms. The allocation of water itself in this framework is basically determined by the conditions for Pareto optimality. The nature of the allocation mechanism used, in particular the structure of the two-level negotiations, can have an impact on the final transfers of numeraire (money) made, through its effect on threat points, but the allocation of water itself is invariant to the choice of the allocation mechanism, provided it is efficient. The simple structure we used, particularly quasi-linear utilities, ensured this property, and allowed us to focus on exploring the different possible structures for international and domestic bargaining.

We now introduce a significant complication. We recognize that the productivity or utility of a given quantity of water will very likely depend on the level of complementary investments. These may be dams, irrigation projects, or even more general complementary investments in agriculture or industry ${ }^{17}$. In this section, we will focus on the implications of such investment, through its timing and its productivity effects, for the conduct and outcome of two-level water negotiations. We will initially take the most simple case, and assume no direct effects of investment on water availability as such, but will discuss relaxing this after we have analyzed the simpler case.

Hence, we still assume that the total availability of water is $\bar{w}$, with each group having a de facto initial allocation of $\bar{w}_{\boldsymbol{i}}$. We now assume, however, that the utility function of group i, evaluated at the initial allocation, is given by

(34) $u_{i}\left(\bar{w}_{i}, k^{j} \overline{y_{i}}\right)=v_{i}\left(\bar{w}_{i}, k^{j}\right)+\bar{y}_{i}$.

Here, $\mathrm{k}^{\mathrm{j}}$ is the investment made by country $\mathrm{j}$. Thus, we are keeping matters simple by assuming that there are no direct externality effects of investment, in addition to assuming that water availability is unaffected by such investments. At this stage, we also assume that investments are made only at the national level: domestic groups do not control them, nor can they make group-specific investments. This assumption will need to be changed, of course, if the groups are regions in a federal system, and we will turn to that subsequently. Note also that the utility function is defined gross of the costs of investment. These are given by the strictly convex, twice differentiable function $c_{j}\left(k^{j}\right)$. We will discuss later how these costs may be shared between the two groups in a country.

${ }^{16}$ Recall also that the cooperative bargaining approach may be viewed as obtaining an approximation to some noncooperative bargaining procedure, involving offers and counteroffers.

${ }^{17}$ For example, the introduction of HYVs of seeds in India - the Green Revolution increased the importance of irrigation and the regular availability of water in general. 
We use the following notation: $\partial v_{i w}, \partial v_{i k}$ denote, respectively, the partial derivative of $\mathrm{v}_{\mathrm{i}}$ with respect to $\mathrm{w}$, and the partial derivative of $\mathrm{v}_{\mathrm{i}}$ with respect to $\mathrm{k}$. We assume that all these derivatives are positive. In the remainder of this section, it is convenient to suppress the $\bar{y}_{\boldsymbol{i}}$ 's, by assuming that they are zero, or that utility is scaled to be measured from the initial numeraire allocation as origin. This reduces inessential notation.

\section{Optimal Allocation of Water and Investments}

First suppose that the investment levels are arbitrarily given. The first order conditions determining the Pareto optimal allocation of water (maximizing total utility) are given by

(35) $\partial v_{i w}\left(w_{i}, k^{j}\right)=\lambda$,

where $\lambda$ is the multiplier associated with the aggregate resource constraint. As long as the utility functions are not additively separable in $\mathrm{w}$ and $\mathrm{k}$, these equations imply that the optimal allocation of water depends on the investments in both countries. Hence, even though there are no direct externalities as a result of the investment, the conditional optimum of water allocation involves a linkage of both countries. What country A does with its investment will affect the optimal amount of water that country B should receive. This effect operates through the aggregate resource constraint. Clearly this will be important in negotiations, and will be an important point in our subsequent analysis.

For example, suppose that we have, for group $\mathrm{i}$ in country $\mathrm{j}$, (36) $v_{\boldsymbol{i}}=w_{\boldsymbol{i}}^{a}\left(k^{j}\right)^{1-a}$.

In this case, we can easily solve explicitly for the conditional optimum allocations of water. For country A and group $\mathrm{i}, \mathrm{i}=1,2$, we have ${ }^{18}$

$$
w_{i}=\frac{k^{A} \bar{w}}{2\left(k^{A}+k^{B}\right)}
$$

Note that the optimal amount of water for a group in country A decreases with the level of investment by country B, but increases with its own investment. These are consequences of the complementarity of water and investment in the utility functions. We state the point illustrated by this example more formally in the following.

Proposition 6 In our two country model with two groups in each country, the optimal allocation of water in one country will depend on domestic investment in the other country,

${ }^{18}$ With the utility function in (36), (35) becomes $a v_{i} / w_{i}=\lambda$. Hence $w_{i}=(a / \lambda)^{1 /(1-a)} k^{j}$. Adding up across groups and countries gives $2(\mathrm{a} / \lambda)^{1 /(1-\mathrm{a})}\left(\mathrm{k}^{\mathrm{A}}+\mathrm{k}^{\mathrm{B}}\right)=\bar{w}$. Therefore $(\mathrm{a} / \lambda)^{1 /(1-\mathrm{a})}=$ $\bar{w} /\left(\mathrm{k}^{\mathrm{A}}+\mathrm{k}^{\mathrm{B}}\right)$. Substituting this in the expression for $\mathrm{w}_{\mathrm{i}}$ gives (37). Note that (37) does not depend on the preference parameter 'a' because only one good is being reallocated: the rate of substitution between $\mathrm{w}_{\mathrm{i}}$ and $\mathrm{k}^{\mathrm{j}}$ does not matter. 
even in the absence of direct externalities, as long as domestic investment affects the marginal utility of water.

In general, let the conditional optimum amounts of water be denoted by $w_{i}^{*}\left(k^{A}, k^{B}\right)$. Furthermore, let $v_{i}^{*}\left(k^{A}, k^{\boldsymbol{B}}\right)=v_{i}\left(w_{i}^{*}\left(k^{\boldsymbol{A}}, k^{\boldsymbol{B}}\right), k^{\dagger}\right)$. Thus the $\mathrm{v}_{\mathrm{i}}^{*}$ 's are the utilities assuming that whatever the decisions on investments, the allocation of water will be optimal conditional on those decisions. Finally, for country A, let

$$
V_{A}^{*}\left(k^{A}, k^{B}\right)=v_{1}^{*}\left(k^{A}, k^{B}\right)+v_{2}^{*}\left(k^{A}, k^{B}\right)
$$

with a similar expression for country $B$. These are the gross utilities, before the costs of investment are subtracted off. It will be convenient to work with these functions.

We can now simply note that the optimal choice of investments (maximizing the sum of net welfare in the two countries) is given by the following first order conditions:

$$
\begin{aligned}
& \partial V_{A k^{A}}^{*}\left(k^{A}, k^{B}\right)+\partial V_{B k^{A}}^{*}\left(k^{A}, k^{B}\right)=c_{A}^{\prime}\left(k^{A}\right) \\
& \partial V_{A k^{B}}^{*}\left(k^{A}, k^{B}\right)+\partial V_{B k^{B}}^{*}\left(k^{A}, k^{B}\right)=c_{B}^{\prime}\left(k^{B}\right)
\end{aligned}
$$

These equations determine the optimal investments, and hence the optimal allocation of water is determined by the functions $\mathrm{w}_{\mathrm{i}}{ }^{*}$.

Now suppose that both investments and the allocation of water are the subject of international negotiations. The above solution will determine the Pareto frontier. The outcome of the negotiations will include a joint agreement on the allocation of water between the countries, as well as a joint agreement on the levels of domestic investment in the two countries. This part of the outcome will be invariant to the specific form of the negotiations, as long as the cooperation on both dimensions is possible. However, the specific form of the negotiations will affect the money transfers that accompany the agreement, as we saw in the previous section. Suppose that, for brevity, we restrict attention to case 'ID' from that section. The threat point for the international negotiations is the outcome of successful domestic negotiations in the absence of an international agreement. Since we are assuming that the domestic investments have not been precommitted, but are included in the international negotiations, they are potentially different for the threat situation. Clearly, we can work out the domestic investments for this case, of only domestic negotiations, in two steps as before. The first step is to obtain the optimal domestic reallocation of water given an arbitrary investment level (and now this no longer depends on investment in the other country, since there are no direct externalities). This reduces the problem to the investment dimension, and the national government can choose the optimal level of investment.

At this stage, we need to address the issue of how costs of the national investment are to be allocated to the two groups. If we were to think of this being done through a market or market-like mechanism, where groups would pay user charges based on operating and capacity costs, we could derive the appropriate allocation of the joint costs of the investment through a standard exercise, to ensure optimal usage of capacity. Here, we make no 
distinction between capacity and its utilization, and we shall simply assume that the national government decides on a particular split of the costs, say 50:50. Note that if this is outside the control of the domestic groups, it does not affect their behavior, and the split is irrelevant in the aggregate since utilities of groups are merely added up to obtain the national level objective function.

\section{Noncooperative Investments}

While domestic investments such as dams may plausibly be the subject of international negotiation - and have been in cases where there are direct externalities such as effects on water availability in another country ${ }^{19}$ - it is less likely that countries are willing or able to negotiate broadly at the international level over general investments that affect the utility or productivity of water in the domestic economy. Hence, we turn to an examination of the consequences of noncooperative investment behavior.

We introduce another piece of notation to make our expressions more compact. Let $V_{A}^{A}\left(k^{A}\right)$ denote the total utility in country A (gross of investment costs) in the absence of an international agreement on water. Note that in this case, there is no externality. There is a similar expression for country B. This amount is relevant for the threat point of the international bargaining. Each country is forward-looking in its investment decisions, which are now assumed to be precommitted before the international bargaining takes place. The international negotiation is now only over water. Following the standard solution for the relevant Nash bargaining game, the outcome of the international bargaining for country $\mathrm{A}$ is (40) $\frac{1}{2}\left[V_{A}^{*}\left(k^{A}, k^{B}\right)+V_{B}^{*}\left(k^{A}, k^{B}\right)-c_{A}\left(k^{A}\right)-c_{B}\left(k^{B}\right)+\left(V_{A}^{A}\left(k^{A}\right)-c_{A}\left(k^{A}\right)\right)-\left(V_{B}^{B}\left(k^{B}\right)-c_{B}\left(k^{B}\right)\right)\right]$ The first four terms together give the Pareto optimal aggregate utility, conditional on the domestic investments, while the next two pairs are the disagreement payoffs or threat points for A and B respectively. Because we are now assuming that the investments are precommitted, they are the same with or without an international agreement.

Each country now chooses its investment to maximize its own utility, anticipating the effect on the international bargaining outcome. For country A, the solution satisfies the first order condition

$$
\text { (41) } \frac{1}{2}\left[\partial V_{A k^{A}}^{*}\left(k^{A}, k^{B}\right)+\partial V_{B k^{A}}^{*}\left(k^{A}, k^{B}\right)+\partial V_{A k^{A}}^{A}\right]=c_{A}^{\prime}\left(k^{A}\right)
$$

For country B, a similar condition is obtained. Clearly, these are different from the case where the domestic investments are chosen cooperatively.

Note also that the outcome is different from the simple noncooperative case, where each country myopically chooses investment to maximizes its utility, taking the other country's investment as given. For example, if country A were to choose its domestic

${ }^{19}$ Here the Farakka Dam on the Ganges in India, and its effects on Bangladesh, as well as the proposed Unity Dam on the Yarmouk for Syria, Jordan and Israel, come to mind. 
investment noncooperatively, but not recognizing the strategic implications for future international negotiations, its choice would satisfy ${ }^{20}$

$$
\partial V_{A k^{A}}^{*}\left(k^{A}, k^{B}\right)=c_{A}^{\prime}\left(k^{A}\right)
$$

This also is not optimal, but in a different way. A comparison of these cases is useful.

Suppose that $V_{B}^{*}\left(k^{A}, k^{B}\right)$ did not depend on investment in country A. Then the ordinary noncooperative solution, (42), would coincide with the cooperative solution, given in equation (39). However, the strategic noncooperative solution would still be different from the cooperative solution. ${ }^{21}$ We summarize the above in the following.

Proposition 7 In our two country model with two groups in each country, if domestic investment affects the marginal utility of water, then, even in the absence of direct externalities, negotiating only over water, and not over domestic investments leads to an inefficient outcome if domestic investments can be precommitted.

It is easy to introduce complications into the above model of investments that are complementary to water use. These include allowing for investments to directly affect water availability, or create direct externality effects. It is also easy to allow for asymmetries in the effects of such investments: this would be the case for an upstream versus a downstream country. Clearly, our reduced form expressions above can encompass such cases. A different extension is to allow group-specific investments. This would be plausible if the groups are regional, and there is a federal system in the country in question. Similar considerations will clearly apply at the level of domestic groups: if they can, they will choose their investments strategically, to affect the outcome of subsequent negotiations, both domestic and international.

Investment may be thought of still more broadly. It is commonly argued that international water negotiations are often "linked" to other negotiations, such as arms control and security. The treatment of "investment" here is entirely general. One could think of it as the necessary steps to be taken in arms control, for example, rather than as building a dam. The point is the need for difficult-to-reverse steps which affect overall utility, changing threat points and affecting the credibility of commitments in a repeated game. We leave more detailed examination of this case to future work.

A different sort of modification is the following. Return to the case of national-level investments. Suppose that international negotiations take place before national level

${ }^{20}$ Note that the left hand side of this expression is the partial derivative of (38), which does incorporate the allocation of water.

21 It is useful to point out that, while our model is quite different in scope and implications, as well as specific formulation, from that of Grossman and Hart (1986), the central insight is similar. 
investments are determined. Then, if all agreements over water are binding, the choices of domestic investments will be made given allocations of water. Since the allocations of water will be different at the threat points, the domestic investments in that case will also be different than in the case of international agreement. Now, forward-looking negotiators will recognize the effects of their agreement on investment as well. For example, for country A, the objective function will have the form

$$
v_{1}\left(w_{1}, k^{A}\left(w_{1}, w_{2}\right)\right)+v_{2}\left(w_{2}, k^{A}\left(w_{1}, w_{2}\right)\right)-c_{A}\left(k^{A}\left(w_{1}, w_{2}\right)\right)
$$

The negotiation at the international level can be thought of as proceeding as follows. The two countries can work out the full optimum in terms of water allocations and domestic investments. The international agreement, which can only be over water by assumption, implements the optimal allocation of water corresponding to the optimal domestic investments. Now if each country can decide its level of investment before the domestic negotiations take place, since there are no externalities, it will independently choose the optimal level of domestic investment. This is because the possibility of affecting water allocations through investments, which was the focus of the previous analysis, and the source of inefficiency there, does not arise in this case.

Now suppose that domestic negotiations also take place before the domestic investment decisions are made. This is plausible in that investment decisions may take time, while domestic negotiations can follow quickly on an international agreement. We have treated the international agreement as including a domestic allocation of water for each group, but it may actually only be binding at the level of international transfers of water and money (in opposite directions). This did not matter earlier, since investment was fixed or precommitted in all those cases. Now, however, the possibility arises that, given the overall international agreement, the domestic groups will negotiate over the internal distribution of water, taking account of the fact that the internal distribution will affect domestic investment decisions. However, if the national government always responds by maximizing total net utility, it is easy to see by the envelope theorem that the condition for the optimal allocation of water is unaffected by this possibility.

The discussion in the preceding two paragraphs can be summarized in the following result, formally proved in an Appendix.

Proposition 8 In our two country model with two groups in each country, whether or not domestic investments can be precommitted before internal negotiations, if they take place after international negotiations, then, in the absence of direct externalities, the outcome in terms of water allocation and domestic investments is fully efficient.

This result says that in our simple framework the timing of domestic investments matters only relative to the timing of international negotiations, not relative to the domestic negotiations, as long as the latter come after the international negotiations. It applies only to the case of national level investments. It is easy to extrapolate, however, to the case of group 
(region) specific investments, where the implication would be that their timing relative to domestic negotiations will affect the efficiency of the outcome.

\section{Concluding Remarks}

In this paper, we have begun the task of understanding the outcome of two level (international and domestic) negotiations for the allocation of a good, using the framework of the Nash bargaining solution, and the case of water. This can be viewed as obtaining an approximation to a particular, but plausible, noncooperative bargaining procedure. The use of the Nash bargaining solution distinguishes our analysis from those of Lax and Sebenius (1991), Iida (1993), and Mo (1995). Mayer (1992) uses the Nash bargaining approach, but less formally, and to ask a different set of questions. The contributions of our analysis are two-fold. First, we compare different simultaneous and two-level bargaining situations, showing when and why some might yield equivalent outcomes. Second, we highlight the importance of the nature and timing of complementary investments, and whether they are included in negotiations, in affecting the efficiency of the negotiated outcome. While the equivalence results are sensitive to our particular formulation, the lessons of the analysis of investment are not restricted to any functional form.

We have not explored specifically the possibility of investments that affect the other nation's threat point, for example through the possibility of military action. This is an interesting issue, closely related to the issue of lack of well-defined initial property rights, but one that requires a separate, detailed analysis. Here, we simply note that we have throughout assumed that the bargaining takes place from well-defined initial positions, reflecting legal or de facto property rights. Thus, we focus on the mutual benefits of trade, and how to achieve them optimally. The issue of conflict over initial property rights is less tractable, and must be tackled as an inherently noncooperative game, since gains for one party mean losses for another.

The main insights of our analysis do not rely on the presence of uncertainty or lack of information. However, it will be interesting in future work to extend our analysis to allow for both. In addition to extending our work to allow for uncertainty and lack of information, we will also examine the effect of having self-interested governments that also respond to political pressure, as in recent work by Grossman and Helpman (1995a, 1995b). This will introduce a significant additional dimension to the problem. 


\section{Appendix}

\section{Proof of Proposition 8}

Let $\mathrm{V}_{\mathrm{j}}\left(\mathrm{w}_{\mathrm{j}}, \mathrm{k}^{\mathrm{j}}\right)$ be the gross utility of country $\mathrm{j}$, assuming water is allocated optimally within each country. The optimum involves choosing $\mathrm{w}_{\mathrm{A}}, \mathrm{w}_{\mathrm{B}}, \mathrm{k}^{\mathrm{A}}, \mathrm{k}^{\mathrm{B}}$ to maximize

(A1) $\mathrm{V}_{\mathrm{A}}\left(\mathrm{w}_{\mathrm{A}}, \mathrm{k}^{\mathrm{A}}\right)+\mathrm{V}_{\mathrm{B}}\left(\mathrm{w}_{\mathrm{B}}, \mathrm{k}^{\mathrm{B}}\right)-\mathrm{c}_{\mathrm{A}}\left(\mathrm{k}^{\mathrm{A}}\right)-\mathrm{c}_{\mathrm{B}}\left(\mathrm{k}^{\mathrm{B}}\right)$ subject to $\mathrm{w}_{\mathrm{A}}+\mathrm{w}_{\mathrm{B}}=\bar{w}$.

The first order conditions are

$$
\begin{aligned}
& \partial V_{A w_{A}}=\partial V_{B w_{B}} \\
& \partial V_{A k^{A}}=c_{A}^{\prime}\left(k^{A}\right) \\
& \partial V_{B k^{B}}=c_{B}^{\prime}\left(k^{B}\right) .
\end{aligned}
$$

The case where domestic negotiations follow domestic investment, which follows the international water agreement, is straightforward. The Nash bargaining solution in country A (country $\mathrm{B}$ is similar) requires maximizing (with respect to $\mathrm{w}_{1}, \mathrm{w}_{2}$ )

$$
\left(u_{1}\left(w_{1}, k^{A}\right)-\frac{1}{2} c_{A}\left(k^{A}\right)-d_{1}\right)\left(u_{2}\left(w_{2}, k^{A}\right)-\frac{1}{2} c_{A}\left(k^{A}\right)-d_{2}\right) \text { subject to } \mathrm{u}_{1}+\mathrm{u}_{2}=\mathrm{u}_{\mathrm{A}}{ }^{*} \text {, where }
$$

$\mathrm{u}_{\mathrm{A}} *$ is the (net) national level welfare from the international water agreement, assuming an optimal domestic water allocation, but conditional on investment.

The Nash bargaining solution for group 1 (group 2 is similar) is

$$
u_{1}=\frac{1}{2}\left[u_{A}\left(w_{A}^{*}, k^{A}\right)-c\left(k^{A}\right)+d_{1}-d_{2}\right] \text {. }
$$

Maximizing (A4) with respect to $\mathrm{k}^{\mathrm{A}}$ gives the required first order condition for optimality.

Now, consider the case where domestic bargaining is before domestic investment, but again after the international water agreement. Now, potentially we have $\mathrm{k}^{\mathrm{A}}\left(\mathrm{w}_{1}, \mathrm{w}_{2}\right)$, instead of a fixed $\mathrm{k}^{\mathrm{A}}$ in (A3), including in the constraint. The Nash bargaining solution is still as in (A4), but group 1, for example gets

(A5) $\frac{1}{2}\left[v_{1}\left(w_{1}, k^{A}\left(w_{1}, w_{2}\right)\right)+v_{2}\left(w_{2}, k^{A}\left(w_{1}, w_{2}\right)\right)-c_{A}\left(k^{A}\left(w_{1}, w_{2}\right)\right)\right]$.

Here the potential dependence of investment on the domestic bargaining outcome is made explicit. Maximizing this subject to $\mathrm{w}_{1}+\mathrm{w}_{2}=\mathrm{w}_{\mathrm{A}}$ yields the first order condition $\partial v_{1 w_{1}}+\left(\partial v_{1 k^{A}}+\partial v_{2 k^{A}}-c_{A}^{\prime}\right) \partial k_{w_{1}}^{A}=\lambda$.

However, the term in parentheses is zero, since the national government will choose $\mathrm{k}^{\mathrm{A}}\left(\mathrm{w}_{1}, \mathrm{w}_{2}\right)$ to maximize national welfare. Therefore the outcome will be the same as if $\mathrm{k}^{\mathrm{A}}$ were given to the domestic groups.

This completes the proof of the proposition. 


\section{References}

Barrett, Scott, (1994), "Conflict and Cooperation in Managing International Water Resources", Policy Research Working Paper no. 1303, The World Bank, May.

Binmore, Kenneth, Ariel Rubinstein, and Asher Wolinsky, (1986), "The Nash Bargaining Solution in Economic Modelling", Rand Journal of Economics, 17, 2, Summer, 176-188.

Chaudry, M., and M.H. Siddigi, (1987), "Toward a National Water Plan in Bangladesh", Chapter 34 in Water Resources Policy for A sia, ed., Mohammed Ali, George Radosevich, Akbar Ali Khan, Boston: A.A. Balkema.

Crow, Ben, with Alan Lindquist and David Wilson (1995), Sharing the Ganges: The Politics and Technology of River Development, Sage Publications: New Delhi.

Dhillon, P.S., (1983), A Tale of Two Rivers, Chandigarh: Dhillon Publishers.

Fisher, Franklin M., (1995), "The Economics of Water Dispute Resolution, Project Evaluation and Management: An Application to the Middle East", Water Resources Development, 11, 4, 377-389.

Friedkin, Joseph F., (1987), "International Water Treaties: United States and Mexico", Chapter 25 in Water Resources Policy for A sia, ed., Mohammed Ali, George Radosevich, Akbar Ali Khan, Boston: A.A. Balkema.

Grossman, Gene and Elhanan Helpman (1995a), "Trade Wars and Trade Talks", Journal of Political Economy, 103, 4, August, 675-708.

Grossman Gene and Elhanan Helpman (1995b), "The Politics of Free-Trade Agreements", American Economic Review, 85, September, 667-690.

Grossman, S., and O. Hart, (1986), "The Costs and Benefits of Ownership: A Theory of Vertical and Lateral Integration", Journal of Political Economy, 94, 4, August, 691-719.

Harsanyi, J.C., (1963), "A Simplified Bargaining for the n-Person Cooperative Game", International Economic Review, 4, 194-220.

Harsanyi, J. C., (1977), Rational Behavior and Bargaining Equilibrium in Games and Social Situations, Cambridge: Cambridge University Press.

Iida, Keisuke, (1993), "When and How Do Domestic Constraints Matter? Two Level Games with Uncertainty", Journal of Conflict Resolution, 37, 3, September, 403-426. 
Just, Richard E., Sinaia Netanyahu, and John K. Horowitz, (1996), "Water Pricing and Water Allocation in Israel", processed, University of Maryland, Department of Agricultural Economics.

Krishna, Vijay, and Roberto Serrano, (1996), "Multilateral Bargaining", Review of Economic Studies, 63, 1, 61-80.

Lax, David A., and James K. Sebenius, (1991), "Negotiating Through an Agent", Journal of Conflict Resolution, 35, 3, September, 474-493.

Lensberg, T., (188), "Stability and the Nash Solution", Journal of Economic Theory, 45, 330341.

Mayer, Frederick W., (1992), "Managing Domestic Differences in International Negotiations: The Strategic Use of Internal Side-Payments", International Organization, 46, 4, Autumn, 793818.

Mo, Jongryn, (1995), "Domestic Institutions and International Bargaining: The Role of Agent Veto in Two-Level Games", American Political Science Review, 89, December, 914-924.

National Water Development Agency, (1992), National Perspectives for Water Resources Development, July, New Delhi: NWDA.

Putnam, Robert D., (1988), "Diplomacy and Domestic Politics: The Logic of Two-Level Games", International Organization, 42, 427-460.

Ramana, M.V.V., (1992) Inter-State River Water Disputes in India, Madras: Orient Longman. Rubinstein, Ariel, (1982), "Perfect Equilibrium in a Bargaining Model", Econometrica, 50, 1, 97-109.

Schelling, Thomas, (1960), The Strategy of Conflict. Oxford and London: Oxford University Press.

World Bank, (1993), Water Resources Management: A World Bank Policy Paper. Washington, D.C.: The World Bank. 